\title{
Seasonal ARIMA model to Nigerian consumer price index data Ette Harrison ETUK
}

\author{
Department of Mathematics/Computer Science, Rivers State University of Science and \\ Technology, NIGERIA. Email: ettetuk@yahoo.com
}

\begin{abstract}
Time series analysis of Nigerian Consumer Price Index (NCPI) Data is done. It is observed that it is seasonal. A multiplicative seasonal autoregressive integrated moving average (ARIMA) model, $(0,1,1) \times(0,1,1)_{12}$, is fitted to the series. A visual inspection of the actual and the fitted time plots reveals a close agreement between the two.
\end{abstract}

Key Words: Consumer Price Index, Seasonal Time Series, ARIMA model, Nigeria

\section{INTRODUCTION}

A time series is defined as a set of data collected sequentially in time. It has the property that neighbouring values are correlated. This tendency is called autocorrelation. A time series is said to be stationary if it has a constant mean and variance. Moreover the autocorrelation is a function of the lag separating the correlated values and called the autocorrelation function (ACF).

A stationary time series $\left\{X_{t}\right\}$ is said to follow an autoregressive moving average model of orders $p$ and $q$ (designated $\operatorname{ARMA}(p, q)$ ) if it satisfies the following difference equation

$$
X_{t}+\alpha_{1} X_{t-1}+\alpha_{2} X_{t-2}+\ldots+\alpha_{p} X_{t-p}=\varepsilon_{t}+\beta_{1} \varepsilon_{t-1}+\beta_{2} \varepsilon_{t-2}+\ldots+\beta_{q} \varepsilon_{t-q}
$$

or

$$
\mathrm{A}(\mathrm{B}) \mathrm{X}_{\mathrm{t}}=\mathrm{B}(\mathrm{B}) \varepsilon_{\mathrm{t}}
$$

where $\left\{\varepsilon_{t}\right\}$ is a sequence of random variables with zero mean and constant variance, called a white noise

process, and the $\alpha_{i}$ 's and $\beta_{j}$ 's constants; $A(B)=1+$ $\alpha_{1} B+\alpha_{2} B^{2}+\ldots+\alpha_{p} B^{p}$ and $B(B)=1+\beta_{1} B+\beta_{2} B^{2}+$ $\ldots+$

$\beta_{\mathrm{q}} \mathrm{B}^{\mathrm{q}}$ and $\mathrm{B}$ is the backward shift operator defined by $B^{k} X_{t}=X_{t-k}$.

If $p=0$, model ( 1 ) becomes a moving average model of order $q$ (designated $M A(q))$. If, however, $\mathrm{q}=0$ it becomes an autoregressive process of order $p$ (designated $A R(p))$. An $A R(p)$ model of order $p$ may be defined

as a model whereby a current value of the time series $X_{t}$ depends on the immediate past $p$ values: $X_{t-1}, X_{t-2}$, ...,

$\mathrm{X}_{\mathrm{t}-\mathrm{p}}$. On the other hand an MA(q) model of order $\mathrm{q}$ is such that the current value $X_{t}$ is a linear combination of immediate past values of the white noise process: $\varepsilon_{1}, \varepsilon_{2}, \ldots, \varepsilon_{\mathrm{q}}$. Apart from stationarity, invertibility is another important requirement for a time series. It refers to the property whereby the covariance structure of the series is unique (Priestley, 1981). Moreover it allows for meaningful association of current events with the past history of the series (Box and Jenkins, 1976).

An $A R(p)$ model may be more specifically written as

$$
\mathrm{X}_{\mathrm{t}}+\alpha_{\mathrm{p} 1} \mathrm{X}_{\mathrm{t}-1}+\alpha_{\mathrm{p} 2} \mathrm{X}_{\mathrm{t}-2}+\ldots+\alpha_{\mathrm{pp}} \mathrm{X}_{\mathrm{t}-\mathrm{p}}=\varepsilon_{\mathrm{t}}
$$

Then the sequence of the last coefficients $\left\{\alpha_{i i}\right\}$ is called the partial autocorrelation function(PACF) of $\left\{X_{t}\right\}$. The ACF of an MA(q) model cuts off after lag $q$ whereas that of an $A R(p)$ model is a combination of sinusoidals dying off slowly. On the other hand the PACF of an MA(q) model dies off slowly whereas that of an $A R(p)$ model cuts off after lag $p$. AR and MA models are known to have some duality properties. These include:

1. A finite order $A R$ model is equivalent to an infinite order MA model.

2. A finite order MA model is equivalent to an infinite order AR model. 
3. The ACF of an AR model exhibits the same behaviour as the PACF of an MA model.

4. The PACF of an AR model exhibits the same behaviour as the ACF of an MA model.

5. An AR model is always invertible but is stationary if $\mathrm{A}(\mathrm{B})=0$ has zeros outside the unit circle.

6. An MA model is always stationary but is invertible if $B(B)=0$ has zeros outside the unit circle.

Parametric parsimony consideration in model building entails preference for the mixed ARMA fit to either the pure AR or the pure MA fit. Stationarity and invertibility conditions for model (1) or (2) are that the equations $A(B)=0$ and $B(B)=0$ should have roots outside the unit circle respectively. Often, in practice, a time series is non-stationary. Box and Jenkins (1976) proposed that differencing of an appropriate data could render a non-stationary series $\left\{X_{t}\right\}$ stationary. Let degree of differencing necessary for stationarity be $d$. Such a series $\left\{X_{t}\right\}$ may be modelled as

$$
\left(1+\sum_{i=1}^{p} \alpha_{i} B^{i}\right) \nabla^{d} X_{t}=\mathrm{B}(\mathrm{B}) \varepsilon_{\mathrm{t}}
$$

where $\nabla=1-\mathrm{B}$ and in which case $\mathrm{A}(\mathrm{B})=$ $\left(1+\sum_{i=1}^{p} \alpha_{i} B^{i}\right) V^{d}=0$ shall have unit roots $d$ times.

Then

differencing to degree $d$ renders the series stationary. The model (3) is said to be an autoregressive integrated

moving average model of orders $p, d$ and $q$ and designated ARIMA(p, d, q).

Seasonal ARIMA Models: A time series is said to be seasonal of order $d$ if there exists a tendency for the series to exhibit periodic behaviour after every time interval $d$. Traditional time series methods involve the identification, unscrambling and estimation of the traditional components: secular trend, seasonal component, cyclical component and the irregular movement. For forecasting purpose, they are reintegrated. Such techniques could be quite misleading.

The time series $\left\{X_{t}\right\}$ is said to follow a multiplicative $(\mathrm{p}, \mathrm{d}, \mathrm{q}) \times(\mathrm{P}, \mathrm{D}, \mathrm{Q})_{\mathrm{s}}$ seasonal ARIMA model if

$$
\mathrm{A}(B) \Phi\left(B^{s}\right) \nabla^{d} \nabla_{s}^{D} X_{t}=\mathrm{B}(B) \Theta\left(B^{s}\right) \varepsilon_{t}
$$

where $\Phi$ and $\Theta$ are polynomials of order $P$ and $Q$ respectively. That is,

$$
\begin{array}{r}
\Phi\left(B^{s}\right)=1+\phi_{1} B^{s}+\ldots+\phi_{P} B^{s P}, \\
(5) \\
\Theta\left(B^{s}\right)=1+\theta_{1} B^{s}+\ldots+\theta_{Q} B^{s Q},
\end{array}
$$

where the $\phi_{i}$ and $\theta_{j}$ are constants such that the zeros of the equations (5) and (6) are all outside the unit circle

for stationarity and invertibility respectively. Equation (5) represents the autoregressive operator whereas (6) represents the moving average operator.

Existence of a seasonal nature is often evident from the time plot. Moreover for a seasonal series the ACF or correlogram exhibits a spike at the seasonal lag. Box and Jenkins (1976) and Madsen (2008) are a few authors that have written extensively on such models. A knowledge of the theoretical properties of the models provides basis for their identification and estimation. The purpose of this paper is to fit a seasonal ARIMA

model to Nigerian Consumer Price Index series.

\section{MATERIALS AND METHODS}

The data for this work are monthly composite consumer price index series from March 1963 to December 2003 obtainable from Abstracts of the National Bureau of Statistics of Nigeria.

Determination of the orders $d, D, p, P, q$ and $Q$ : Seasonal differencing is necessary to remove the seasonal trend. If there is secular trend non-seasonal differencing will be necessary. To avoid undue model complexity it has been advised that orders of differencing $d$ and $D$ should add up to at most 2 (i.e. $d+D<3$ ). If the ACF of the differenced series has a positive spike at the seasonal lag then a seasonal AR component is suggestive; if it has a negative spike then a seasonal MA term is suggestive.

As already mentioned above, an $A R(p)$ model has a PACF that truncates at lag $p$ and an $M A(q))$ has an ACF that truncates at lag $q$. In practice $\pm 2 / \sqrt{ } n$ where $\mathrm{n}$ is the sample size are the non-significance limits for both functions. 
Model Estimation: The involvement of the white noise terms in an ARIMA model entails a nonlinear iterative process in the estimation of the parameters. An optimization criterion like least error of sum of squares, maximum likelihood or maximum entropy is used. An initial estimate is usually used. Each iteration is expected to be an improvement of the last one until the estimate converges to an optimal one. However,for pure AR and pure MA models linear optimization techniques exist (See for example Box and Jenkins (1976), Oyetunji (1985)). There are attempts to adopt linear methods to estimate ARMA models (See for example, Etuk(1987,1996)). We shall use Eviews software which employs the least squares approach involving nonlinear iterative techniques.

Diagnostic Checking: The model that is fitted to the data should be tested for goodness-of-fit. We shall do some analysis of the residuals of the model. If the model is correct, the residuals would be uncorrelated and would follow a normal distribution with mean zero and constant variance. The autocorrelations of the residuals should not be significantly different from zero.

\section{RESULTS AND DISCUSSION}

The time plot of the original series NCPI in Figure1 clearly depicts a positive trend. Seasonal (i.e. 12month) differencing of the series produces a series SDNCPI with less trend (see Figure 2). Seasonality is not very evident. Non-seasonal differencing yields a series DSDNCPI with no trend and no clear seasonality (see Figure 3 ). Its ACF in Figure 4 has a negative spike at lag 12 revealing a seasonality of lag 12 and a seasonal

MA component to the model. The PACF shows no spike in the early lags $(1,2,3, \ldots)$ suggesting a nonseasonal

MA component. We therefore propose a $(0,1,1) \times(0$, $1,1)$ seasonal model. That means

$$
\text { DSDNCPI } I_{t}=\beta_{1} \varepsilon_{t-1}+\beta_{12} \varepsilon_{t-12}+\beta_{13} \varepsilon_{t-13}+\varepsilon_{t}
$$

The estimation of the model is summarized in Table 1. The fitted model is given by
Table 1: model estimation dependent variable: dsdncpi

\begin{tabular}{|c|c|c|c|c|}
\hline \multicolumn{5}{|c|}{$\begin{array}{l}\text { Method: Least Squares } \\
\text { Date: 01/14/12 Time: } 15: 56 \\
\text { Sample(adjusted): } 1964: 04 \text { 2003:12 } \\
\text { Included observations: } 477 \text { after adjusting endpoints } \\
\text { Convergence achieved after } 17 \text { iterations } \\
\text { Backcast: } 1963: 03 \text { 1964:03 }\end{array}$} \\
\hline Variable & Coefficient & Std. Error & t-Statistic & Prob. \\
\hline $\mathrm{MA}(1)$ & -0.024021 & 0.046292 & -0.518899 & 0.6041 \\
\hline $\mathrm{MA}(12)$ & -0.743270 & 0.039797 & -18.67631 & 0.0000 \\
\hline $\mathrm{MA}(13)$ & -0.021166 & 0.052572 & -0.402612 & 0.6874 \\
\hline R-squared & 0.341303 & \multirow{6}{*}{\multicolumn{2}{|c|}{$\begin{array}{l}\text { Mean dependent var } \\
\text { S.D. dependent var } \\
\text { Akaike info criterion } \\
\text { Schwarz criterion } \\
\text { F-statistic } \\
\text { Prob(F-statistic) }\end{array}$}} & 2.464780 \\
\hline Adjusted R-squared & 0.338523 & & & 56.60452 \\
\hline S.E. of regression & 46.03714 & & & 10.50304 \\
\hline Sum squared resid & 1004604. & & & 10.52925 \\
\hline Log likelihood & -2501.976 & & & 122.8011 \\
\hline Durbin-Watson stat & 2.009975 & & & 0.000000 \\
\hline Inverted MA Roots & $\begin{array}{c}.98 \\
.49+.84 i \\
-.48+.84 i \\
-.97\end{array}$ & $\begin{array}{r}.85+.49 i \\
.00-.98 i \\
-.48-.84 i\end{array}$ & $\begin{array}{r}.85-.49 i \\
.00+.98 i \\
-.84+.49 i\end{array}$ & $\begin{array}{c}.49-.84 i \\
-.03 \\
-.84-.49 i\end{array}$ \\
\hline
\end{tabular}

$\operatorname{DSDNCPI}_{\mathrm{t}}+0.024021 \varepsilon_{\mathrm{t}-1}+0.743270 \varepsilon_{\mathrm{t}-12}+0.021166 \varepsilon_{\mathrm{t}-13}=$ $\varepsilon_{\mathrm{t}}(8)$

$\begin{array}{lll}( \pm 0.046292) & ( \pm 0.039797) \quad( \pm 0.052572)\end{array}$

The estimation involved 17 iterations. Clearly only $\beta_{12}$ is significantly different from zero, being larger than twice its standard error. There is considerable agreement between the actual and the fitted models as shown in Figure 5. The correlogram of the residuals in Figure 6 depicts the adequacy of the model. Virtually all the autocorrelations are not significantly different from zero.

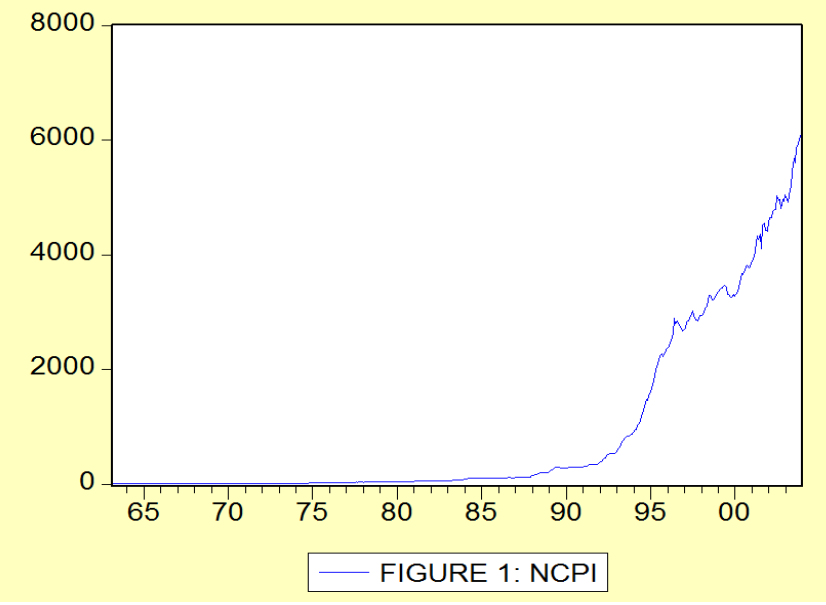



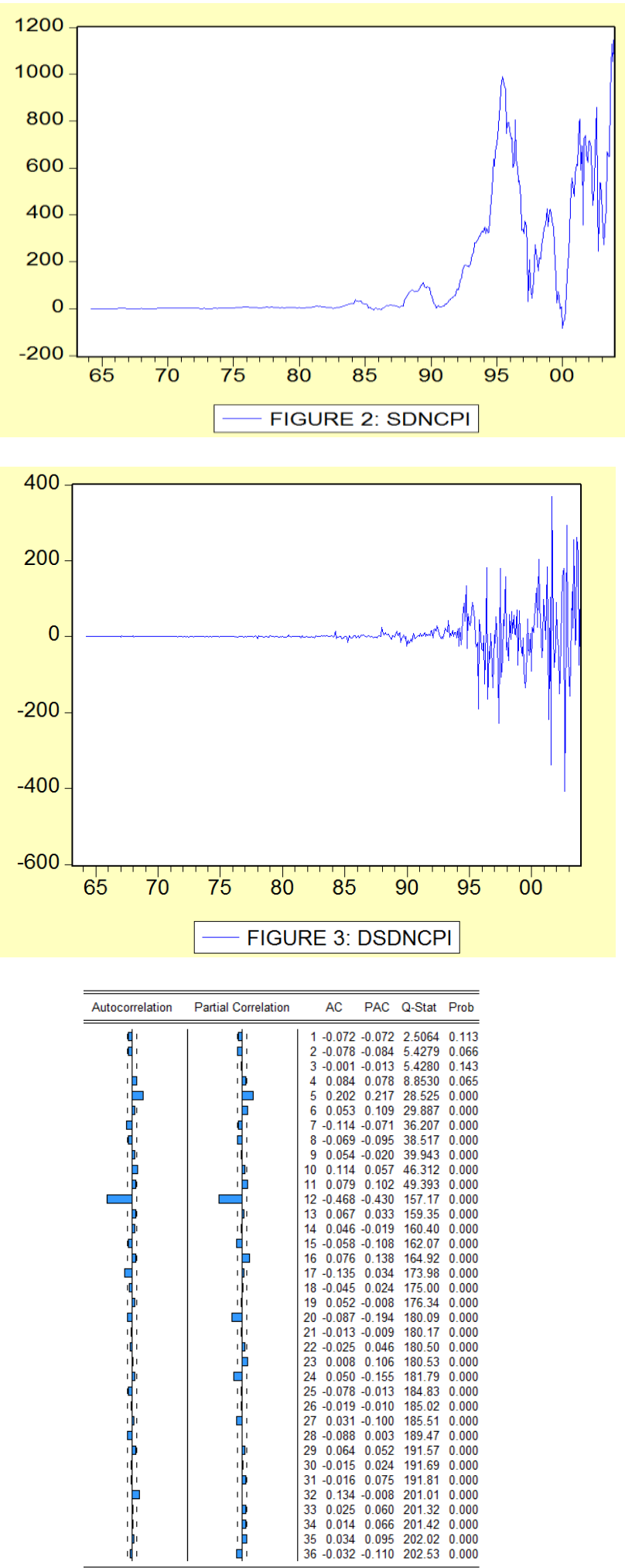

Fig 4: Correlogram of DSDNCPI

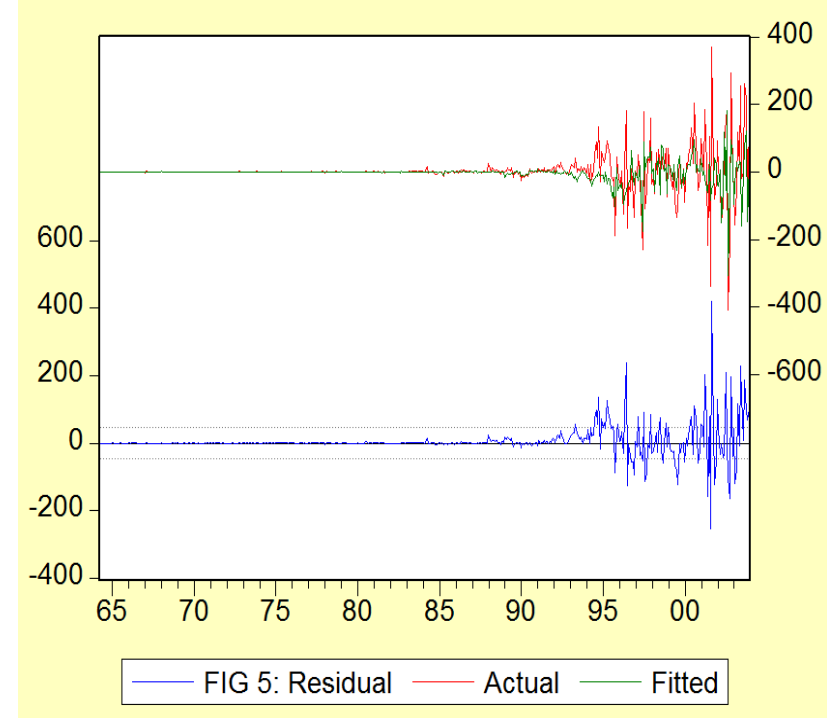

\begin{tabular}{|c|c|c|c|c|c|c|}
\hline Autocorrelation & Partial Correlation & & $\mathrm{AC}$ & PAC & Q-Stat & Prob \\
\hline | & I & & -0.025 & -0.025 & 0.3098 & \\
\hline i] & i] & & 0.053 & 0.052 & 1.6456 & \\
\hline 16 & if & & 0.049 & 0.052 & 2.8249 & \\
\hline ש & ש & 4 & 0.115 & 0.115 & 9.2040 & 0.002 \\
\hline صر & ص & & 0.205 & 0.211 & 29.543 & 0.000 \\
\hline 10 & 10 & & 0.064 & 0.072 & 31.509 & 0.000 \\
\hline$\sqrt{11}$ & 1) & & -0.012 & -0.036 & 31.580 & 0.000 \\
\hline$\sqrt{1}$ & 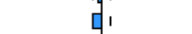 & & -0.044 & -0.092 & 32.506 & 0.000 \\
\hline if & 小 & 9 & 0.079 & 0.018 & 35.592 & 0.000 \\
\hline שر & 1 & 10 & 0.135 & 0.097 & 44.486 & 0.000 \\
\hline$\sqrt{11}$ & 16 & 11 & 0.053 & 0.055 & 45.873 & 0.000 \\
\hline 10 & 10 & 12 & -0.052 & -0.042 & 47.216 & 0.000 \\
\hline 11 & 11 & 13 & -0.006 & -0.014 & 47.233 & 0.000 \\
\hline if & $1 / 1$ & 14 & 0.077 & 0.037 & 50.160 & 0.000 \\
\hline 10 & 0 & 15 & -0.031 & -0.092 & 50.647 & 0.000 \\
\hline ק & if & 16 & 0.115 & 0.088 & 57.257 & 0.000 \\
\hline a & $\sqrt{1}$ & 17 & -0.064 & -0.023 & 59.313 & 0.000 \\
\hline 舟 & ता & 18 & -0.029 & -0.027 & 59.741 & 0.000 \\
\hline if & it & 19 & 0.065 & 0.044 & 61.874 & 0.000 \\
\hline$\sqrt{1}$ & {$[1$} & 20 & -0.063 & -0.091 & 63.869 & 0.000 \\
\hline i] & if & 21 & 0.096 & 0.068 & 68.510 & 0.000 \\
\hline$\sqrt{11}$ & 15 & 22 & 0.043 & 0.092 & 69.430 & 0.000 \\
\hline il & 111 & 23 & 0.017 & 0.033 & 69.579 & 0.000 \\
\hline 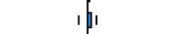 & $1 / 1$ & 24 & 0.030 & 0.025 & 70.024 & 0.000 \\
\hline 0 & 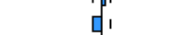 & $\begin{array}{l}24 \\
25\end{array}$ & -0.067 & $\begin{array}{r}-0.094 \\
\end{array}$ & 72.265 & 0.000 \\
\hline is & 11 & 26 & 0.078 & 0.018 & 75.360 & 0.000 \\
\hline $1 \pi$ & in & 27 & 0.035 & 0.013 & 75.977 & 0.000 \\
\hline 0 & $d$ & 28 & -0.059 & -0.072 & 77.729 & 0.000 \\
\hline ith & if & 29 & 0.050 & 0.072 & 79.017 & 0.000 \\
\hline$\sqrt{1}$ & $1 \sqrt{1}$ & 30 & -0.022 & -0.004 & 79.268 & 0.000 \\
\hline Ti & 11 & 31 & 0.003 & -0.011 & 79.273 & 0.000 \\
\hline if & 1) & 32 & 0.064 & 0.019 & 81.403 & 0.000 \\
\hline 16 & י & 33 & 0.025 & 0.027 & 81.730 & 0.000 \\
\hline 16 & קו & 34 & 0.054 & 0.098 & 83.239 & 0.000 \\
\hline$\sqrt{11}$ & $1 \sqrt{1}$ & 35 & 0.011 & -0.003 & 83.297 & 0.000 \\
\hline 14 & 101 & 36 & -0.035 & -0.054 & 83.941 & 0.000 \\
\hline
\end{tabular}

Fig 6: Correlogram Of The Residuals

\section{CONCLUSION:}

The NCPI series has been shown to follow a $(0,1$, 1) $x(0,1,1)_{12}$ model. This model has been shown to be adequate. 


\section{REFERENCES:}

1. Box, G. E. P. And Jenkins, G. M. (1976). Time Series Analysis, Forecasting and Control, Holden-Day, San Francisco.

2. Etuk, E. H. (1987). On the Selection of Autoregressive Moving Average Models. An unpublished Ph. D. Thesis, Department of Statistics, University of Ibadan, Nigeria.

3. Etuk, E. H. (1996). An Autoregressive Integrated Moving Average (ARIMA) Model:
A Case Study. Discovery and Innovation, Volume 10, Nos. 1 \& 2: pp. $23-26$.

4. Madsen, H. (2008). Time Series Analysis, Chapman \& Hall/CRC, London.

5. Oyetunji, O. B. (1985). Inverse Autocorrelations and Moving Average Time Series Modelling. Journal of Official Statistics, Volume 1: pp. $315-322$.

6. Priestley, M. B. (1981). Spectral Analysis and Time Series. Academic Press, London. 